\title{
Experiência de um estágio curricular em Terapia Ocupacional na atenção primária: foco nas necessidades em saúde infantil
}

\author{
Experience in a curricular internship in primary \\ care occupational therapy: focus on infant health needs \\ Teresa Cristina Brito Ruas ${ }^{1}$, Fernanda Castilho Leite ${ }^{1}$, Marco Akerman², Heloisa Ravanini Gagliardo ${ }^{3}$ \\ ${ }^{1}$ Curso de Terapia Ocupacional, Faculdade de Medicina do ABC (FMABC) - Santo André (SP), Brasil. \\ ${ }^{2}$ Disciplina de Saúde Coletiva, FMABC - Santo André (SP), Brasil. \\ ${ }^{3}$ Centro de Estudos e Pesquisas em Reabilitação (Cepre), Universidade Estadual de Campinas (UNICAMP) - Campinas (SP), Brasil.
}

DOI: http://dx.doi.org/10.7322/abcshs.v40i3.813

\section{RESUMO}

Introdução: A atenção à saúde infantil no Brasil enfrenta problemas reais na execução efetiva de ações transformadoras de suas práticas, capazes de responder às demandas individuais e coletivas no que se refere a sua promoção, proteção e recuperação. Relato de experiência: Este estudo trata da experiência de alunos do quarto ano de Terapia Ocupacional (TO) — em uma unidade básica de saúde (UBS) da cidade de Santo André — na implantação e no desenvolvimento de ações voltadas à atenção primária à saúde infantil em um estágio curricular obrigatório desde 2010. Neste relato foram enfocadas as atividades - guiadas pelo princípio metodológico reflexão-ação-reflexão — desenvolvidas na brinquedoteca e no acompanhamento do desenvolvimento infantil. Conclusão: Essa experiência com crianças em situação de vulnerabilidade social e/ou biológica tem nos mostrado a urgência em aproximar a instituição de ensino superior das necessidades locais em saúde, tornando possível uma prática profissional com ações capazes de reconhecer e fornecer recursos para potencializar e acompanhar as características próprias da infância.

Palavras-chave: terapia ocupacional; saúde infantil; promoção em saúde; prevenção de doenças; aprendizagem baseada na experiência; extensão comunitária.

\begin{abstract}
Introduction: Attention to infant health in Brazil faces real problems concerning the effective accomplishment of transforming actions related to its practices, capable of meeting individual and collective demands related to its promotion, protection and recovery. Experience report: This study deals with the experience acquired by $4^{\text {th }}$ year students of the Occupational Therapy course in a Basic Health Unit in the Santo André city with the implantation and development of actions related to the primary attention to the infant health in a Mandatory Curricular Probation since 2010. This report focuses the activities - guided by the methodological principle - reflection-action-reflection, developed in the toy room and in the monitoring of infant development. Conclusion: This experience acquired from children in a situation of social and/ or biological vulnerability has shown us the urgent necessity of approaching the university to the local health necessities, thus enabling a professional practice with actions capable of recognizing and providing resources to empower and monitor the infant own characteristics.
\end{abstract}

Keywords: occupational therapy; infant health; health promotion; diseases prevention; experience-based learning: community extension. 


\section{INTRODUÇÃO}

\section{O campo de estágio: cenário e objetivos}

O objetivo deste relato é apresentar uma experiência de estagiários do quarto ano de Terapia Ocupacional da Faculdade de Medicina do ABC (FMABC) - elaborada sob as Diretrizes e Normas Regulamentadoras de Pesquisas Envolvendo Seres Humanos, de acordo com a Resolução 466/12 (do Conselho Nacional de Saúde), e aprovada pelo Comitê de Ética e Pesquisa da FMABC, com o protocolo $\mathrm{n}^{\circ}$ 01083112.6.0000.0082 - na implantação e no desenvolvimento de ações voltadas à atenção primária à saúde (APS) na infância, em uma unidade básica de saúde (UBS) em Santo André, desde 2010.

Os alunos do curso supracitado desenvolviam, com os agentes comunitários de saúde e os alunos do $4^{\circ}$ ano do curso de Enfermagem da mesma instituição, ações e programas para a população idosa dessa comunidade. Portanto, até 2010 não existia um conjunto de ações desenvolvidas pela Terapia Ocupacional (TO) para atender às demandas e às necessidades da saúde infantil nesse local. Nesse sentido, resgatamos o que construímos de 2010 a 2012 e buscamos identificar os atuais desafios para a continuidade de nossas ações para a promoção da saúde infantil.

Primeiramente, quando pensamos em desafios na saúde, temos de frisar que a atenção à saúde no Brasil, especialmente a voltada para a infância/adolescência, enfrenta problemas reais na execução efetiva de ações transformadoras de suas práticas, capazes de responder às demandas individuais e coletivas no que se refere a sua promoção, proteção e recuperação ${ }^{1,2}$.

Tal situação tem sido comprovada cotidianamente nas instituições de saúde de caráter público e privado. Observa-se que os usuários, profissionais e estudantes convivem, por um lado, com a discrepância de políticas universais, equitativas e descentralizadas - princípio central da Constituição Federal de 1988, com a criação do Sistema Único de Saúde (SUS) - e, por outro, com o conservadorismo das práticas de saúde, centradas em um modelo assistencial, medicalizante e hospitalocêntrico ${ }^{1-3}$.

Diante dessa realidade, as ações nas UBSs e suas comunidades podem ser uma estratégia que prioriza e favorece os princípios do SUS na atenção à saúde individual e coletiva, por meio de práticas que viabilizam o conhecimento do contexto social, histórico e cultural no processo saúde-doença. Portanto, apresentam-se como uma possibilidade de proposição de novas práticas em saúde que substituem o modelo tradicional de assistência - orientado para os sintomas e a cura das doenças - , promovendo o empoderamento coletivo e a transformação social, e que vão além das práticas usuais ${ }^{3,4}$.

Assim, na tentativa de promover outras ações em saúde que viabilizem a história individual/coletiva, a integralidade e a orientação familiar/comunitária fundamentadas nos princípios da promoção/acompanhamento da saúde e da prevenção de doenças, o curso de TO da FMABC começou a desenvolver projetos e intervenções que vão além dos espaços terapêuticos tradicionais, recorrendo a dispositivos que buscam a ampliação do contexto social/cultural, da autonomia e da melhoria da qualidade de vida das crianças e de suas famílias, as quais se encontram em situação de vulnerabilidade e/ou exclusão/desfiliação social ${ }^{5}$.

\section{RELATO DE EXPERIÊNCIA}

\section{Conceitos e dispositivos importantes para a prática contextualizada}

\section{A relevância profissional na formação acadêmica}

A TO, ao longo de todo o seu processo histórico e de constituição como um campo específico de conhecimento, busca evidências empíricas e sociais que objetivam uma ocupação humana capaz de auxiliar o sujeito/grupo e/ou a coletividade a compreender as necessidades e a definir estratégias para lidar com as dificuldades cotidianas, respeitando os diferentes momentos e as possibilidades dos envolvidos ${ }^{6-8}$.

Sabe-se que essa profissão, justamente por seu saber interdisciplinar e multifacetário ${ }^{9}$, tem a possibilidade de abarcar as multidimensionalidades do existir humano, por ter os conhecimentos das ciências biológicas, humanas e sociais, possui diferentes possibilidades para a intervenção. Desde ações criativas e potencializadoras no cotidiano da comunidade, como a atuação em UBSs, a relação profissional com os agentes comunitários, a construção de espaços de convivência, até as iniciativas de articulação social com os diversos setores da sociedade e da esfera pública.

Apesar de toda a nova política para ações de promoção, proteção, recuperação da saúde, equidade, universalidade e integralidade, os terapeutas ocupacionais, em sua maioria, ainda ocupam lugares especializados, como centros de atenção psicossocial, hospitais, ambulatórios de especialidades, centros de reabilitação e instituições ${ }^{10}$, e pouco se vê esse profissional inserido em espaços como as UBSs, os centros de convivência comunitários, os programas da saúde da família e aqueles para o acompanhamento da infância e adolescência.

Atualmente, e desde as reformas sociais ocorridas no Brasil, a partir de 1980, a docência em TO tem se preocupado em fomentar experiências pedagógicas/práticas e discussões que viabilizam e mostram, aos alunos, a capacidade profissional em atingir a universalidade, a integralidade, a equidade, a participação social e, portanto, a potência interdisciplinar em desenvolver atividades que promovam a saúde, segundo os atuais critérios da rede de serviços de referência. Quando redirecionamos a nossa prática profissional e o nosso arcabouço científico e de conhecimento para outras possibilidades de ação, diferentemente do que encontramos no modelo biomédico e hospitalocêntrico, temos de vislumbrar que a TO extrapola o campo da saúde e promove emancipação e autonomia para que o sujeito assuma o protagonismo de sua vida, apesar das condições físicas, sociais e/ou culturais existentes ${ }^{7}$.

Sabe-se que implantar ações em TO em espaços diferentes dos tradicionais requer um olhar direcionado e crítico para as diversas 
realidades sociais em saúde, frequentemente encontradas em comunidades periféricas e de baixa renda, como a Comunidade do Parque do Capuava em Santo André. Para isso, é necessário um olhar afetivo, contextualizado, com bagagem teórica e prática capaz de lidar com situações-problema de ordem mais complexa, associado a uma leitura da realidade social em saúde e, neste estudo, da saúde infantil de crianças de famílias de baixa renda ${ }^{8}$.

Espera-se que, com esse olhar contextualizado, o aluno possa fazer uma reflexão crítica de qual seria a melhor ação a ser desenvolvida, a fim de responder à demanda trazida pelo usuário, pelos familiares e/ou pelo entorno social. Neste estudo todas as ações desenvolvidas para o acompanhamento e a promoção da saúde infantil foram analisadas/questionadas/aprendidas segundo o princípio metodológico reflexão-ação-reflexão ${ }^{11}$.

É válido ressaltar que o norte teórico que guiou a elaboração e a implementação das ações desenvolvidas nesse estágio não seguiu um único referencial teórico, uma única metodologia e/ou área específica de atuação dentro da TO (física, mental ou social). O que afirmo, como educadora e pesquisadora, é que, neste estudo, não foram realizados e/ou discutidos conceitos/ideologias específicas de uma ou outra área profissional. Discutimos TO orientados por uma visão multifacetária e interdisciplinar, capaz de contextualizar a realidade da saúde infantil da comunidade do Capuava.

Portanto, aspectos da área física, abordando o referencial teórico sobre o desenvolvimento/saúde infantil e a importância de acompanhar "os marcos" da infância, assim como conceitos e realidades que permeiam o campo social, tais como o acolhimento e o favorecimento do livre brincar para crianças de baixa renda, como também a utilização e a compreensão de todos os espaços, tais como a brinquedoteca, foram discutidos e utilizados conforme a demanda apresentada pela UBS, pelos profissionais e pelos usuários.

Assim, este estudo compreendeu e defendeu que, para a promoção da saúde infantil, seguindo os princípios da APS e do SUS, a TO deve ser olhada como um campo de conhecimento multifacetário, interdisciplinar, capaz de permear os diferentes campos das ciências biológicas, humanas e sociais, sem a exclusão ou o "preconceito" de determinada teoria e/ou área específica de atuação. Focar na primeira infância e na realidade social em uma comunidade carente de recursos demanda que o futuro profissional compreenda a importância de analisar as diferentes possibilidades terapêuticas que ele tem em seu arcabouço teórico, na medida em que reconhecemos a complexidade da problemática a ser enfrentada.

\section{DISCUSSÃO}

\section{A realidade social e a formação acadêmica}

Nessa comunidade, encontramos crianças, ainda na primeira infância, que possuem uma rotina de trabalhos domésticos, como cuidar dos irmãos menores e do próprio lar enquanto os pais estão trabalhando, e, portanto, não têm um tempo livre, "com qualidade", destinado à ludicidade, nem tampouco o acompanhamento do desenvolvimento infantil, por meio de programas públicos que promovem a saúde e o bem-estar e/ou previnem possível dificuldade ou agravo.

A realidade das crianças que usam os espaços da TO na UBS reflete uma carência da principal rede provedora de cuidados básicos, de afeto, de proteção e de respeito às características da infância que é, justamente, o núcleo familiar. A grande maioria dos pais e/ou responsáveis legais que buscou os serviços de TO foi de adultos, que sofrem as consequências sociais e econômicas, por exemplo, do analfabetismo funcional, do subemprego, da escassez e/ou da falta de alimentação e/ou de bens de consumo, e que se encontra em uma situação de pobreza e de miséria.

Paralelamente, verificou-se, diante do relato dos usuários, o quanto a região periférica do Parque do Capuava ainda sofre as consequências de uma rede social de suporte não estabelecida para a infância. Há escassez de espaços públicos destinados ao lazer infantil e/ou à permanência das crianças em período integral, como no caso das creches, enquanto os pais trabalham e/ou estão fora de casa.

Vale ressaltar que quando se caracteriza uma situação de vulnerabilidade social, como a citada acima, não se descarta o poder da resiliência latente em cada sujeito e seu núcleo provedor de cuidados e afeto. Sabe-se o quanto essas crianças e famílias são resilientes e o quanto elas buscam e expressam força e potência de vida, mesmo diante de situações muito difíceis. E é justamente por existir esse vigor que essas crianças e famílias chegaram até os serviços de promoção e proteção à saúde infantil, como o relatado neste estudo.

Quando observamos essa realidade social e a necessidade urgente em elaborarmos ações capazes de promover o bem-estar infantil naquela região periférica, a união da instituição de ensino superior com a comunidade deve ser vista como uma potente ferramenta social e política, que nos permite aumentar nossas frentes de atuação profissional.

Desde o momento da graduação, é importante prezar a responsabilidade social com relação à assistência à infância, ter o reconhecimento de que a criança é um sujeito de direitos como o livre brincar - , constatar que o aluno de TO é um ator político e social e valorizar as atividades humanas como principais meios de emancipação, socialização e expressão.

Nesse sentido, nossas ações e nossos conhecimentos técnicos foram configurados, a partir de uma realidade profissional e pedagógica capaz de construir, para as crianças da comunidade, um espaço de relevância social que contemplasse a percepção individual, o exercício do poder e o direito de brincar livremente como formas potentes de expressão da vida.

Já é possível observar alguns resultados positivos, como a ampliação do acesso aos cuidados da saúde infantil, a partir do direito do livre brincar e do acompanhamento do desenvolvimento pueril durante os primeiros anos de vida, como uma ação capaz de proteger e/ou recuperar algum agravo à saúde. Todos os resultados são indicativos de maiores 
possibilidades para a promoção do bem-estar, da integralidade e da qualidade da infância.

\section{Dispositivos para a formação acadêmica e as necessidades locais: brinquedoteca, brincadeiras e confecção de brinquedos}

Sabemos que ainda estamos em fase de construção de uma metodologia de trabalho em um serviço de APS, no espaço de articulação entre a prática e o ensino. Verificamos, a partir das reflexões dos alunos do primeiro grupo de estágio em 2010, com os professores da TO e os agentes comunitários, a necessidade de incrementar a livre participação social das crianças em atividades e espaços lúdicos capazes de promover o direito do livre brincar e da exploração/experimentação das potencialidades humanas infantis por meio dos brinquedos e das brincadeiras ${ }^{10,11}$.

Diante do próprio objetivo lúdico da brinquedoteca e da necessidade de maior participação/empoderamento social das crianças e famílias usuárias desse espaço público de saúde, decidiu-se por manter brinquedoteca aberta à comunidade todos os dias da semana, podendo ser utilizada por qualquer criança que fosse à UBS para consultas médicas, vacinação e/ou acompanhamento pela TO e/ou outra especialidade.

Além dessa ação, criada para fortalecer os laços e a rede social da comunidade, principalmente no que tange ao quadro de privação de espaços públicos destinados ao brincar, à livre circulação e ao encontro das crianças, acordamos que todos os dias, no período entre $8 \mathrm{~h}$ e $12 \mathrm{~h}$, uma aluna de $4^{\circ}$ ano de TO, responsável pela brinquedoteca, estaria ali e toda quinta-feira, das $13 \mathrm{~h} 30$ às $18 \mathrm{~h}$, os alunos do estágio curricular na área de desenvolvimento infantil, relatado nesta experiência, ficariam no local.

Apesar de ser um espaço livre para a circulação de qualquer profissional da equipe de saúde, a presença majoritária da TO na brinquedoteca foi bastante discutida e refletida entre os alunos do estágio.

Dialogamos com os alunos que podemos considerar a brinquedoteca e os diferentes espaços lúdicos como lugares para experimentação, conhecimento e construção das habilidades, experiências e vivências infantis que podem ser potencializadas pela livre exploração lúdica ${ }^{12}$.

As autoras supracitadas relatam que é no espaço sociocultural da brinquedoteca que se deve estabelecer uma relação entre o conhecimento e a sua construção. A partir das experiências lúdicas infantis, motivadas pela curiosidade natural dessa fase da vida, a ação humana pode encontrar a sua concretude e o seu significado, favorecendo uma melhor qualidade de vida, saúde, participação social e cidadania na infância.

Oliveira ${ }^{1}$ afirma que a criação de brinquedotecas, em vários países e no Brasil, teve como objetivo a valorização e o resgate da ação lúdica pelo livre brincar, a qual caracteriza a ocupação humana infantil, essencial para promover e potencializar a saúde de toda e qualquer criança. Saúde que é compreendida, aqui, como um processo e como um atributo à própria condição de "ser" e "estar vivo".

Assim, brincar livremente em espaços lúdicos, como as brinquedotecas, é uma forma de manter a criança viva e potente para que ela continue tendo a percepção de quais são os caminhos que podem garantir a ela criatividade, autonomia e bem-estar e, portanto, estratégias para manter o "fio condutor" de sua própria vida.

Além disso, percebemos que o fortalecimento da rede social dessa comunidade não requeria apenas o fornecimento de um espaço lúdico e/ou recurso material pronto, como os brinquedos industrializados, para conseguirmos o resgate da ação lúdica pelo brincar. Era necessário, também, resgatar a participação social das famílias nas atividades próprias da criança, tentando sensibilizar e conscientizar os adultos sobre a importância e a necessidade de garantir aos filhos o direito do livre brincar, principalmente na primeira infância.

A brinquedoteca se transformou em um espaço muito importante para trocas e conversas entre alunos e responsáveis legais das crianças sobre o desenvolvimento infantil, a importância do livre brincar, a confecção de brinquedos de baixo custo/com material reciclado e sobre possíveis atividades lúdicas que poderiam ser desenvolvidas em família. Além disso, também se tornou em um espaço "multifacetário" nas ações desenvolvidas pela $\mathrm{TO}$, sendo um recurso terapêutico e um ambiente importante e eficaz para acolher as diferentes demandas e necessidades apresentadas pelas crianças e seus pais.

Desde o início do estágio, alunos e educadora responsável observaram que essa troca de conhecimentos com os responsáveis legais, a partir da escuta e do acolhimento de cada família, poderia ocorrer na brinquedoteca, enquanto as crianças exploravam livremente os diversos brinquedos e as brincadeiras propostos pelos alunos e/ou escolhidos por elas mesmas.

Essa ação com os pais foi potencializada nesse espaço, pois se acredita que a família deve ser enfocada como promotora e responsável pela saúde infantil, considerando-se que o sucesso de ações que promovam a saúde, a integralidade, a participação social e a cidadania ocorre, também, quando centralizamos a atenção nas famílias que vivem no entorno e frequentam o serviço público de saúde local.

Sabe-se que, quando a família recebe o suporte social para se tornar promotora da saúde e dos direitos da infância, torna-se "empoderada"13, ou seja, passa de uma posição passiva de ser mera receptora de serviços para ser um agente de transformação social, capaz de mudar e enfrentar com dignidade as múltiplas adversidades da vida.

A ação de empoderar as famílias é respaldada por políticas universais, igualitárias e descentralizadas - como princípio central da Constituição Federal de 1988, com a criação do SUS, o que se contrapõe com o conservadorismo das práticas de saúde, centradas em um modelo assistencial, medicalizante e hospitalocêntrico ${ }^{1,2}$.

Verificou-se que, nas diversas experiências propostas na brinquedoteca do Capuava, o aluno de TO teve a oportunidade de compreender, na prática e na teoria, que o livre brincar, além de um recurso terapêutico fundamental, é, primeiramente, uma área de ocorrência de experiências singulares, as quais permitem a inserção da criança que brinca e aprende em uma cultura compartilhada, responsabilizando-a pela construção de seu cotidiano e sua saúde, dividindo com os pais e/ou responsáveis legais esse processo de descoberta e aprendizagem ${ }^{12,14}$. 
Esta experiência gerou uma compreensão mais real do objetivo de "Por que brincar" e de como ela possibilitaria, realmente, a melhoria da saúde das crianças. Os alunos, ao final desse estágio, demonstraram, em suas ações lúdicas, que as atividades propostas, além de recursos técnicos e terapêutico ocupacionais, eram, também, uma forma de construir a cultura no cotidiano, permitir a expressão de práticas singulares das crianças pertencentes à comunidade do Capuava e possibilitar a compreensão do ser humano como um ser criativo e livre para experimentar e expressar a sua natureza ocupacional lúdica ${ }^{10,14}$.

\section{O acolhimento das crianças e das famílias}

Em relação à promoção do desenvolvimento infantil, verificamos que a ação de acompanhar as principais etapas e os comportamentos nos primeiros anos de vida caracteriza-se por um conjunto de medidas que abrange a promoção/proteção da saúde infantil e a prevenção dos agravos, diante do diagnóstico e encaminhamento precoce para o tratamento e a reabilitação, quando necessário. Portanto, acompanhar o desenvolvimento de toda criança, em seus primeiros anos de vida, é um atributo da APS, principalmente diante da possibilidade de ter uma equipe de saúde capaz de acompanhar o indivíduo em todos os momentos de seu ciclo de vida, abordando as problemáticas de forma sistêmica, relacionando-as à realidade territorial, social, cultural e econômica ${ }^{1,10}$.

Considerando essas premissas, a TO e a pediatria desenvolveram um serviço para acolher e acompanhar o desenvolvimento infantil global (aspectos motores, cognitivos, sensoriais e afetivos) de toda criança de 0 a 3 anos, independentemente de ter ou não algum fator de risco para seu desenvolvimento, que passasse pela pediatria e/ou vacinação na UBS do Capuava.

As crianças que não apresentavam fatores de risco e/ou alterações no desenvolvimento, geralmente, passavam por uma avaliação/triagem e os responsáveis legais recebiam orientações sobre a infância, a alimentação e a importância do brincar, além de ficarem livres para voltarem ao serviço quando tivessem dúvidas e/ou observado algo que pudesse ser um risco para o crescimento de seu filho. As com algum fator de risco biológico e/ou social, geralmente prematuras, com baixo peso, desnutridas e/ou em situação de exclusão/desfiliação social diante da falta de alimentação e/ou moradia adequadas, são acompanhadas até o final do terceiro ano de vida. Essas passam uma vez por mês por todas as ações desenvolvidas pelo estágio e, diante do diagnóstico precoce, pela equipe, de alguma alteração, são encaminhadas para novos exames e/ou para o centro de habilitação e reabilitação do Hospital Mário Covas.

Esse acompanhamento e essas orientações específicas foram realizados pelos alunos de TO e pelos residentes em pediatria, utilizando-se de seus conhecimentos técnicos específicos sobre o desenvolvimento infantil normal nos primeiros três anos de vida e os possíveis sinais que caracterizariam alguma alteração/agravo à saúde infantil.

Tal procedimento acontecia em consultório da UBS, no qual havia uma maca pediátrica, lavatório, mesa e cadeiras. Os recursos utilizados eram: um aro vermelho para a realização da triagem das funções visuais (segundo o Método de Avaliação da Conduta
Visual em Lactentes, proposto por Gagliardo ${ }^{15}$ ), lanterna, brinquedos sonoros, coloridos, com diferentes texturas, de encaixe simples e aqueles para a simbolização. As crianças que não apresentavam marcha e/ou não tinham completado um ano de idade eram avaliadas, exclusivamente, nos consultórios. As que apresentavam marcha e/ou tinham mais de um ano de idade também podiam ser avaliadas na brinquedoteca.

$\mathrm{Na}$ Comunidade do Capuava, permeada pela necessidade social que reflete na saúde das crianças, percebemos o quanto essa ação de promoção do desenvolvimento infantil vem se tornando um conjunto de medidas rápidas, eficazes e com baixo custo financeiro, capazes de efetivar os princípios da promoção à saúde infantil e da prevenção de agravos.

Assim, verifica-se que esta experiência, além de favorecer a vivência prática e teórica sobre as principais etapas que toda criança deve passar nos primeiros anos de vida, possibilitou, também, o entendimento da realidade social das crianças e dos familiares atendidos. Percebemos que a TO, com a pediatria, teve a oportunidade de promover uma intervenção interdisciplinar, baseada na integralidade da criança, desconstruindo ações puramente organicistas, excludentes e alienantes que ainda caracterizam outros modelos de atuação em saúde.

\section{O que ficou de tudo isso?}

Esta experiência mostra o quanto as particularidades e especificidades de cada agravo/necessidade determinam uma abordagem e um conhecimento clínico específicos. No entanto, sabemos que mesmo o processo de saúde-doença sendo uma configuração biológica, é também uma realidade constituída por um indivíduo (que é um personagem social). Isso significa que, como princípio ético, as práticas de saúde devem instrumentalizar os futuros profissionais a buscarem, por meio de políticas e práticas sociais, possibilidades que mais aproximem as pessoas excluídas da condição de vida cidadã, garantindo a elas os serviços necessários de promoção e acompanhamento da saúde infantil, como as ações desenvolvidas neste estudo.

Há uma urgente necessidade de promover mais espaços de atenção, de escuta e de acolhimento das demandas e realidades sociais das comunidades usuárias dos serviços públicos de saúde. Esse processo pode ser potencializado com a aproximação da universidade das comunidades regionais e do SUS, visando a produção de conhecimento e o desenvolvimento de tecnologias/metodologias que proporcionem a resolubilidade de problemáticas sociais apresentadas pela comunidade, como os princípios doutrinários da APS.

Todos os envolvidos nesta experiência puderam perceber como as UBSs superam as formas tradicionais de intervenção e proporcionam ações voltadas para o contexto e o cotidiano do indivíduo e de sua comunidade, além de compreenderem que o entendimento da realidade social, diante da gama de possibilidades de intervenção da TO, é uma forma potente de desconstruir ações puramente organicistas, excludentes e alienantes e precisa ser constituído/ construído em todo o processo de formação acadêmica. 


\section{REFERÊNCIAS}

1. Oliveira DC, Sá CP, Gomes AMT, Ramos RS, Pereira NA, Santos WCR. A política pública de saúde brasileira: representação e memória social de profissionais. Cad Saúde Pública. 2008;24(1):197-206.

http://dx.doi.org/10.1590/S0102-311X2008000100020

2. Rodrigues MP, Lima KC, Roncalli AG. A representação social do cuidado no programa saúde da família na cidade de Natal. Ciênc Saúde Coletiva. 2008;13(1):71-82.

http://dx.doi.org/10.1590/S1413-81232008000100012

3. Westphal MF. Promoção da saúde e prevenção de doenças. In: Campos GWS, Minayo MCS, Akerman M, Drumond M, Carvalho YM (orgs.). São Paulo: Hucitec; 2006; p.635-88.

4. Segre M, Ferraz FC. O conceito de saúde. Rev Saúde Pública. 1997;31(5):538-42.

http://dx.doi.org/10.1590/S0034-89101997000600016

5. Jurdi APS, Brunello MIB, Honda M. Terapia Ocupacional e propostas de intervenção na rede pública de ensino. Rev Ter Ocup Univ São Paulo. 2004;15(1):26-32.

http://dx.doi.org/10.11606/issn.2238-6149.v15i1p26-32

6. Lopes RE. Cidadania, políticas públicas e terapia ocupacional. Tese (Doutorado) - Faculdade de Educação da Universidade Estadual de Campinas, Campinas, 1999.

7. Barros DD, Lopes RE, Galheigo SM. Projeto Metuia Terapia Ocupacional no Campo Social. Mundo Saúde. 2002;26(3):365-9.
8. Galheigo SM. O social: idas e vindas de um campo de ação em Terapia Ocupacional. In: Pádua EMM, Magalhães LV. Terapia Ocupacional: teoria e prática. Campinas: Papirus; 2003. p.29-46.

9. Morin E, Almeida M C, Carvalho EA. Educação e complexidade: os sete saberes e outros ensaios. Editora Cortez; São Paulo: 2000. p.102.

10. Aoki M, Oliver FC, Nicolau SM. Pelo direito de brincar: Conhecendo a infância e potencializando a ação da Terapia Ocupacional. Rev Ter Ocup Univ São Paulo. 2006; 17(2):57-63. http://dx.doi.org/10.11606/issn.2238-6149.v17i2p57-63

11. Freire, P. Pedagogia da autonomia. São Paulo: Paz \& Terra; 2003. p. 20-45

12. Malfitano APS, Braga IF, Silva KG, Motta NG. A Promoção de direitos de crianças e adolescentes em situação de vulnerabilidade social: oficina de brincadeiras como recurso. Cad Ter Ocupacional UFSCar. 2006:14(2):103-110.

13. Dessen MA, Silva NLP. A família e os programas de intervenção: tendências atuais. In: Mendes EG, Almeida MA, Williams LCA (orgs.). Temas em Educação Especial: avanços recentes. São Carlos: EdUFSCar; 2004.

14. Takatori M. O brincar na Terapia Ocupacional: um enfoque na criança com lesões neurológicas. São Paulo: Zagodoni; 2012.

15. Gagliardo HGRG, Gonçalves VMG, LimaMCMP, Françoso MFC, Aranha Netto A. Visual function and fine-motor control in small-for-gestational age infants. Arq Neuropsiquiatr. 2004;62(4):955-62. 